Doi: $\underline{10.31578 / j e b s . v 5 i 1.184}$

\title{
Eradicating Poor Achievement in Basic Science and Technology through Learning Activity Package: How Do Students Behave in Nigeria?
}

\author{
Moses Olanrewaju Afuwape* \\ Augustine Lanre Olugbuyi **
}

\begin{abstract}
This study was designed to determine the effects of Learning Activity Package (LAP) teaching method on students' achievement in basic science and technology with special consideration to the moderating effect of learning styles. A pre-test - post-test quasiexperimental design was adopted for the study. Three hypotheses were formulated to guide the study for data collection and analysis. The sample for the study comprised sixty-nine (69) students from two (2) co-educational junior secondary schools in ljebu-Ode local government area of Ogun state, Nigeria. Basic science and technology achievement test (BSAT) and learning styles self-assessment questionnaire were used as instruments in collecting data for the study. Data collected were analysed using ANCOVA and MCA in order to determine the magnitude of students' post-test achievement scores in basic science and technology. Findings of the study showed a significant main effect of teaching strategy on students' academic achievement in basic science and technology $(F(1,57)=8.362, \mathrm{P}<0.05)$. However, no significant main effect of learning styles on students' academic achievement in Basic Science and Technology $(F(1,57)=0.070, P>0.05)$ was revealed, neither any significant interaction effects of teaching strategies were found. Based on the findings, it was recommended that Learning Activity Package (LAP) teaching method should be incorporated into the teaching of basic science and technology at the junior secondary school level. Furthermore, Learning Activity Package should be particularly introduced into system approach to instruction in basic science and technology at all levels of teacher education.
\end{abstract}

Keywords: Learning Activity Package (LAP), teaching method, conventional method, achievement, basic science and technology

\section{Introduction}

Science has been and would continue to be of tremendous importance because of its ability to explain many natural occurrences and the central role it plays in the world's current technology development (Osuolale, 2014; Bilesanmi-Awoderu, Afuwape, \& Jolaosho, 2017). The target individual may be children, college students or adults within the public. The field of science education comprises science content, some social sciences and some teaching pedagogy (Berube, 2008). The standard of science education provides the development of understanding for students throughout their entire course of study. Basic science is a basic subject that lays the foundation for the take-off of sciences (biology, chemistry and physics) in the senior secondary classes. It is regarded as an approach to science in which concepts and principles are presented to express the fundamental unity of scientific thought

\footnotetext{
* Department of Science And Technology Education, Olabisi Onabanjo University, Ago-Iwoye, Ogun State, Nigeria

** Department of Science and Technology Education, Olabisi Onabanjo University, Ago-Iwoye, Ogun State, Nigeria.

Corresponding Email: afuwapemoses@yahoo.com, geostarlight@gmail.com
} 
and to avoid premature or undue stress on the distinctions between various scientific fields (Ogonnaya, Okafor, Abonyi, \&Ugama, 2016).

The National Policy on Education encourages all processes geared towards producing educators and scholars that will encourage the spirit of inquiry (Federal Ministry of Education, 2008). In addition, one of the objectives of primary and junior secondary school education in Nigeria is to inculcate in children permanent literacy and numeracy and the ability to communicate effectively.

The general objective of basic science and technology education is to enable pupils to observe and explore the environment using their senses and hands. The objectives are specifically aimed to enable the learners to:

a. develop interest in science and technology,

b. acquire basic knowledge and skill in science and technology,

c. apply their scientific and technological knowledge and skill to meet their societal needs,

d. take advantage of the numerous career opportunities offered by science and technology and become prepared for further studies in science and technology (Nigeria Educational Research Development Council, 2007).

These objectives are enshrined in the basic science and technology curriculum, derived from the National Policy on Education. The design of the curriculum is based on the idea of spirality of themes that are arranged from Year One to Year Nine, which is beginning with the simple and moving to the more complex across the nine years of basic education.

To achieve the stated objectives of basic science, it calls for effort and encouragement in diverse ways due to benefits therein. Various studies conducted by several empirical researchers (Betiku, (2001); Omole, (2003); Ferdinand (2007) and Ogunnika (2018) have concluded that students' academic achievement in basic science in Nigeria is poor and needs improvement. The poor achievement in basic sciences has attracted the concern of all stakeholders, including researchers. Abonyi and lbe (2014) also noted poor academic achievement in basic science in the studies they carried out. In close resemblance to the reports above is the conclusion made by Oyedeji (2010) where he lamented that Nigeria remains an underdeveloped economy principally because of the unsatisfactory status of her science education especially in the primary and junior secondary school. He further asserted that relevant statistical details on basic science showed that there is crisis in the area of science teaching.

Several factors have been identified as the cause of poor performance in the academic achievement of students in schools. These factors include school- teacher-related characteristics, teaching methods, social incentives, and a host of others (Abonyi \& lbe, 2014; Ogunkola, 2008) concluded that poor methods and strategies of teaching are the major cause of poor academic achievement in basic science. Some other researchers like Mandor (2002), Ezema (2004) and Ekon (2013) have also stated from their findings that one of the major causes of students' failure in basic science is lack of efficient teaching methods.

Teaching methods and strategies are ways used by teachers to create the learning environment and to specify the nature of the activity in which the teacher and the learner will be involved during the instructional delivery process. It is primarily a description of learning objective-oriented activities and the flow of information between the teacher and the learner(s). O'Bannon (2002) categorized teaching methods into two approaches; namely; teacher centered approach and student centeredapproach. The national policy on education advocates for student-centered and activity-oriented approach, as such approach facilitates effective learning of science subjects in schools at all level. Moreover, it has been observed that effective teaching may facilitate learning and make it more meaningful. In line with this assertion, Sander (2001) opined that effective teaching helps the learner to learn better, while poor teaching would naturally lead to poor learning and, consequently, poor achievement. A method 
of teaching, which has been found very effective in delivering instructional contents to secondary school students, is Learning Activity Package (LAP) teaching strategy.

LAP is a student centered, activity-oriented teaching strategy where the teacher acts as a facilitator of learning, guiding the students through a series of activities and problems, which may help learners to achieve highly. In LAP, learning materials are broken into small steps that are arranged sequentially from the known to the unknown and in an increasing order of difficulty (Cardarelli, 1972). LAP is a method that seeks for a way of making teaching more precise, while at the same time adjusting both the objective and methods of learning to the needs and characteristics of individual learners. This innovative method enables each student to work at his/her own pace, thus, accommodating both fast and slow learners. In this method, the goals of the subject matter must be spelt out very well, so that students can arrive at the same goals independently along some avenue other than the one provided by the teacher. From the foregoing, LAP is an individualized method of teaching (Cardarelli, 1972).

LAP strategy has the capability to reach multiple learning styles in a classroom. A learning style is a student's consistent way of responding to and using stimuli in the context of learning. Keefe (1979) defines learning style as the composite of characteristic cognitive, affective and physiological factors that serve as relative stable indicators of how a learner perceives, interacts with and responds to the learning environment. The visual, auditory and kinesthetic (VAK) learning styles use the three main sensory receivers: visual, auditory and kinesthetic to determine the dominant learning style. VAK is derived from the accelerated learning world and seems to be about the most popular model nowadays due to its simplicity (Clark, 2011).

Many educational theorists and researchers (Graf, Kinshuk\& Liu, 2009) view learning styles as an important factor in the learning process. They agree that incorporating them into teaching has the potential to facilitate effective learning for students. It is also believed that students' academic achievement increases when course content is designed and based on the learning styles of the students (Sadeghi, Kasim, Tan \& Abdullah, 2012). When students know their own learning styles and apply them to the learning process, these students are expected to learn both more easily and more rapidly. There is a high degree of probability that the students will be more successful in the learning process, as learning would be encouraged and students would be engaged and motivated (Bennett, 2013). Therefore, there is a need to look at how the instructional strategy (LAP) can interact with the learning style in enhancing learning outcomes in basic science and technology.

\section{Hypotheses}

The following hypotheses were formulated to guide the study:

$\mathrm{H}_{01}$ There is no significant difference between students' academic achievement of those exposed to treatment and those not exposed to it in basic science and technology.

$\mathrm{H}_{02}$ There is no significant difference between the achievement scores of the visual, auditory and kinesthetic students in basic science and technology

$\mathrm{H}_{03}$ There is no significant interaction difference between the achievement scores of the visual, auditory and kinesthetic students in basic science and technology of those exposed to treatment and those not exposed to it.

\section{Methodology}

The study adopted a pre-test - post-test quasi-experimental design. Intact classes were subjected to different treatment conditions. It involved all public junior secondary school two (JSS 2) students in ljebu-Ode local government area of Ogun state, Nigeria. The sample for this study was drawn from the public junior secondary school II basic science and technology students in 
ljebu-Ode local government area of Ogun state. Purposive sampling technique was used to select the schools from the local government. Intact classes were selected in each of the two schools for the study.

The instruments used were:

Treatment Package: Learning Activity Package Instructional Guide (LAPIG)

Measurement instruments: Basic Science and Technology Achievement Test (BSAT)

Classification instrument: Learning Style Self-Assessment test (LSSAT).

LSSAT is a simple and convenient set of 24 Likert-scale questions which takes approximately 10-15 minutes to be completed by respondents. The learning styles tested in this inventory are visual $(\mathrm{V})$, auditory $(\mathrm{A})$, and kinesthetic (K). The LSSAT is in two sections, Section 'A' contains the demographic variables of respondents and section 'B' contains 24 statements with each of the learning style category having 8 items. The items have been assigned scores: 4 points for 'strongly agree' (SA), 3 points for 'agree' (A), 2 points for 'disagree' (D) and 1 point for 'strongly disagree' (SD). The students had to select the description/statement that suits them by putting a tick under the assigned score.

The instrument (LSSAT) was shown to the researcher's supervisor and some other experts in test and measurement who recommended some adjustments to the items of the instruments for better understanding by the respondents. The modifications were made and the instrument was judged as valid for administration. The 24 items of the modified LSSAT were administered on a sample of 50 JSS 2 students outside the main study, but similar in characteristics to the students for whom the instrument was intended in order to re-establish its reliability for the present study. A Cronbach alpha coefficient of 0.84 was obtained.

The procedure for data analysis made use of descriptive and inferential statistics. Mean and standard deviation are the descriptive statistics for the study to show the estimates of the post-test scores according to treatment group. The hypotheses formulated were analyzed using Analysis of Covariance (ANCOVA) with pre-test scores as covariates. The analysis was done at 0.05 level of significance. Multiple Classification Analysis (MCA) was used to explain the magnitude of the post-test mean achievement scores across the different levels of strategy.

\section{Results and Discussion}

The sequence of presentation is in accordance with that of the study hypotheses.

Ho1: There is no significant main effect of treatment (Learning Activity Package (LAP) \& Conventional Method) on students' academic achievement in basic science and technology.

Table 1: Summary of ANCOVA of students' achievement scores in basic science and technology according to treatment (LAP \& Conv.), learning styles and gender

\begin{tabular}{llllll}
\hline Source of Variation & Sum of Squares & df & Mean Square & F & Sig. of F \\
\hline Corrected Model & $842.142^{\mathrm{a}}$ & 11 & 76.558 & 7.212 & .000 \\
Intercept & 572.127 & 1 & 572.127 & 53.894 & .000
\end{tabular}


Covariates (pre-test)

Treatment

Gender

Learning Style

\section{Way Interaction}

Treatment * Gender

Treatment * Learning Style

Gender * Learning Style
484.428

88.768

.474

1.482
484.428

88.768

.474

.741
45.632

.000

005

833

933

\section{Way Interaction}

Treatment * Gender * L/Style

12.678

1

12.678

1.194

.279

\begin{tabular}{|c|c|c|}
\hline Error & 605.104 & 10.616 \\
\hline Corrected Total & 1447.246 & 68 \\
\hline
\end{tabular}

* indicate significant $\mathbf{F}$ at .05 level

R Squared $=.582 \quad($ Adjusted R Squared $=.501)$

Table 1 presents the summary of the analysis of covariance (ANCOVA) test on the effect of treatment, learning style on the students' achievement scores in basic science and technology. It shows the outcome of the main and interaction effects of the two levels of instructional model (Learning Activity Package (LAP) and Conventional Method (CMT) used in the study) and three levels of learning style (visual, auditory and kinesthetic) on students' achievement in Basic Science and Technology. The results revealed a significant main effect of treatment $\left(F_{(1,57)}=8.362, P<0.05\right)$. This implies that there is significant difference in the mean post-test achievement scores of the students after the exposure to the two levels of treatment. As a result, the null hypothesis one was rejected.

The multiple classification analysis (MCA) aspect of the ANCOVA test shows the magnitudes of the mean post-test achievement scores of the participants in the experiment. The MCA, presented in table 2, shows the mean post-test achievement scores of the participants in the three levels of learning styles according to order of magnitudes as well as the contributions of the independent variables to the variance in the dependent variable (achievement in basic science and technology).

Table 2: Multiple classification analysis of students' achievement in basic science and technology according to treatment, gender and learning styles

Grand Mean $=16.530$ 


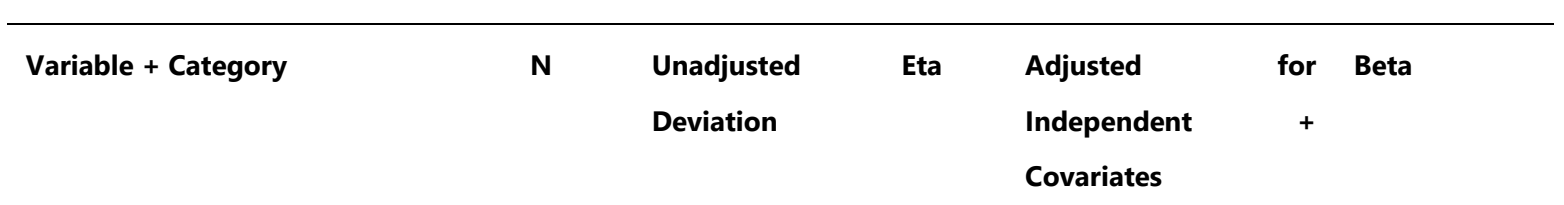

\section{Treatment}

\begin{tabular}{|c|c|c|c|c|c|c|}
\hline 1. & LAP (DCIM) & 30 & 1.980 & & 1.990 & \\
\hline 2. & Conventional Method & 39 & -1.631 & .388 & -1.638 & .389 \\
\hline
\end{tabular}

\section{Gender}

$\begin{array}{lcccc}\text { 1. Male } & 33 & -0.587 & & -0.569 \\ \text { 2. Female } & 36 & 0.516 & \mathbf{. 1 1 9} & 0.500\end{array}$

\section{Learning Style}

$\begin{array}{lcccc}\text { 1. Visual } & 35 & -0.027 & & 0.170 \\ \text { 2. Auditory } & 27 & 0.035 & & -0.569 \\ \text { 3. Kinesthetic } & 07 & 0.042 & \mathbf{. 0 0 7} & 0.087\end{array}$

\begin{tabular}{ll}
.032 \\
\hline
\end{tabular}

Multiple R Squared

\section{* indicate significant $\mathbf{F}$ at .05 level}

Table 2 presents the summary of the MCA analysis and it shows the magnitudes of the adjusted mean post-test achievement scores of students in basic science and technology after the exposure to the two levels of learning strategies. The result shows that with a grand mean of 16.530 , the students exposed to LAP recorded higher adjusted means of the post-test achievement score, 18.520 (i.e. $16.530+1.990$ ) than the students exposed to the conventional method which recorded the adjusted mean of the post-test achievement score of 14.892 (i.e. 16.530 - 1.638). This outcome, thus, shows that LAP Instructional strategy, with the higher adjusted mean post-test achievement score appears to be a better strategy for teaching and improving students' achievement in basic science and technology than the conventional method.

The result in table 2 further reveals that learning strategy as a variable contributed $38.9 \%$ of the variance in the students' achievement scores in basic science and technology while the independent and moderator variables jointly accounted for $16.5 \%$ $(0.406)^{2}$ of the variance in the students' achievement scores in basic science and technology.

$\mathbf{H}_{03}$ There is no significant main effect of learning styles on academic achievement of students in basic science and technology.

The result of the main effect of learning style in tables 1 and 2 show a no-significant main effect of learning style on the students' achievement scores in basic science and technology $\left(F_{(1,57)}=0.070, P>0.05\right)$. This outcome implied that there is no significant difference in the scores obtained by the visual, auditory and kinesthetic participants in achievement scores in basic 
science and technology, i.e. there is no significant main effect of learning style on achievement. As a result, the null hypothesis three is retained.

However, the result of the Multiple Classification Analysis (MCA) on learning style in table 2 showed that with a grand mean of 16.530 , the visual learners with the adjusted mean of the post-test achievement score of 16.700 (i.e. $16.530+0.170$ ) recorded the highest mean achievement score, followed by the kinesthetic learners with the adjusted mean of the post-test achievement score of 16.617 (i.e. $16.530+0.087$ ), while the auditory learners with the adjusted mean of the post-test achievement score of 15.961 (i.e. 16.530 - 0.569) recorded the lowest mean achievement score. This outcome shows that the visual learners recorded the highest achievement scores than the other students with kinesthetic and auditory learning styles in the experiment but the obtained difference is not statistically significant.

$\mathbf{H}_{05}$ There is no significant interaction effect of treatment and learning styles on academic achievement of students in basic science and technology.

The results of the 2-way interaction effect of treatment and learning style in tables 1 and 2 show no significant interaction effect of the treatment and learning styles on the students' achievement scores in basic science and technology $(F(2,57)=3.328, P$ $>0.05)$. This outcome implies that the students' mean post-test achievement scores after the exposure to the two treatments (LAP and CMT) do not vary significantly among the visual, auditory and kinesthetic learners. This means there is no statistically significant difference in the mean post-test achievement scores of the participants having visual, auditory and kinesthetic learning styles after the exposure to the two learning strategies (LAP and Conventional Method). Hence, the null hypothesis five is retained.

\section{Effect of treatment on students' achievement in basic science and technology}

The result of hypothesis 1 (table 1) showed that there is a significant effect of treatment on students' academic achievement in basic science and technology after the exposure to the two methods of teaching in this present study. The results reveal a significant main effect of the two levels of treatment $\left(F_{(1,57)}=8.362, P<0.05\right)$. This implies that there is a significant difference in the mean post-test achievement scores of the students after the exposure to the two levels of treatment. The findings also revealed that both groups of students exposed to the treatments have improvement in achievement scores.

The results further indicated that the Learning Activity Package (LAP) teaching strategy was more effective in improving achievement than the conventional method. The students exposed to LAP recorded the highest adjusted post-test mean achievement score while the conventional method group recorded the lowest adjusted post-test achievement score. This outcome suggests that the Learning Activity Package (LAP) strategy appears to be the best out of the two strategies used in the study for improving achievement in basic science and technology.

The reason for this outcome could be due to the fact that Learning Activity Package (LAP) teaching strategy is an innovative method which enables each student to work at his/her own pace, thus accommodating both the fast and slow learners without having to favour one particular category of students than the other. Another possible reason for this outcome might be because of the fact that the students exposed to Learning Activity Package treatment participated actively in the learning process without the teacher dominating the learning environment. The participants were involved in the process of learning, they felt, touched, arranged and performed experiments during the treatment period. The interactive nature of the Learning Activity Package (LAP) teaching strategy and the prior knowledge (the needs of the learners) provided the framework for fitting new knowledge. 
The findings of this study are in agreement with the results from the findings of Neboh (2009) where he found a statistically significant difference in the achievement of students taught with LAP and conventional method. Neboh (2009) concluded that LAP teaching strategy produces students with higher achievement than students taught with conventional teaching method.

The findings of the present study also agrees with the results of findings from Njoku \& Akamobi (n.d) who found that there is a significant difference between the mean achievement scores of the students in LAP group and the control group, with the LAP group performing higher than the control group. The finding of the present study also corroborated findings of Neboh (2009) who reported that individualized instructional method (LAP) enhanced learning and was more effective than the conventional method of teaching for high school students in physics. Findings from other studies that are in conformity with the findings of the present study are Abu (1998), who found that individualized instructional method (LAP) enhanced the students' achievement without recourse to their previous academic standings, and Burnside (1991), who found that Learning Activity Package was effective for presenting the writing tools using computers. Conclusion from Burnside (1991) also revealed that the students enjoyed independent learning.

\section{Effect of learning styles on the students' academic achievement in basic science and technology}

The results of the main effect of learning styles on the students' academic achievement scores in basic science and technology according to tables 1 and 2 shows non-significant main effect of learning style on the students' achievement scores in basic science and technology $(F(1,57)=0.070, P>0.05)$. This outcome simply means that there is no significant difference in the scores obtained by the visual, auditory and kinesthetic participants in achievement scores, i.e. there is no significant main effect of learning style on achievement of basic science and technology students. However, the results of the Multiple Classification Analysis (MCA) on learning style in table 2 shows that the visual learners obtained the highest achievement scores of all students, although the obtained difference was not statistically significant.

The findings are supported by publication by Abu (2001) and Olurinola (2015) who reported that there was no significant main effect of learning styles on students' achievement in biology and visual arts. Similarly, Adedapo (2013) reported that there was no significant effect of learning style on students' cognitive achievement in microteaching and also no significant interactive effect of microteaching modes and learning styles on students' cognitive achievement in microteaching. The result, however, contradicts the findings of Hattie (2011) who reported that there was a significant effect of learning styles on students' cognitive achievement in learning concepts in physics, while Ogundokun (2011) revealed that learning styles, school environment and test anxiety jointly predicts the learning outcomes. Looking at the two submissions, the results of contradiction could be attributed to the conceptual mode of the subject matters and learners mental abilities.

\section{Interaction effect of treatment and learning styles on the students' academic achievement Basic science and} Technology.

The result of 2-way interaction effect of strategy and learning styles on the students achievement scores in Basic Science and Technology showed no significant effect with $\left(\mathrm{F}_{(2,57)}=3.328, \mathrm{P}>0.05\right)$. This outcome means that the two strategies (LAP \& CM) have the same effect across the three levels of learning styles (visual, auditory and kinesthetic) with respect to achievement in Basic Science and Technology. Findings obtained by the present study can be attributed to the fact that all the students with different learning styles benefitted from the strategy in boosting their academic performance, thus, corroborating the finding of Adedapo (2013) who reported no significant effect of learning style on students' cognitive achievement in microteaching. The 
result however contradicts the finding of Ogundokun (2011) who reported that there was significant effect of learning style on students' cognitive achievement.

\section{Conclusion}

The study investigated the effect of Learning Activity Package teaching method (LAP) on the academic achievement of junior secondary school students in basic science and technology. The conclusions from the major findings are as follows:

- $\quad$ Learning Activity Package teaching method (LAP) teaching strategy can significantly improve students' achievement in basic science and technology. There was difference in mean achievement scores across the strategies and it implies that the use of Learning Activity Package for teaching purpose can improve the teaching and learning of basic science and technology in secondary schools. Learning Activity Package teaching method (LAP) teaching strategy must be used along with many other activities to accommodate students.

Learning style is still a factor in students' academic achievement. Findings revealed that with the use of the strategy, students' achievement with all levels of learning styles, especially the visual style, can be enhanced, since they all have a positive increase in mean scores across all the levels of learning style.

\section{Recommendations}

Based on the findings and conclusions of this study, the following recommendations are made:

- $\quad$ The Learning Activity Package teaching method (LAP) teaching strategy should be incorporated into the teaching of basic science and technology at the secondary school level. This would improve students' academic achievement in basic science and technology.

- Curriculum planners/developers in their efforts to improve the effectiveness of basic science and technology teachers, should encourage the adoption of the Learning Activity Package teaching method (LAP) teaching strategy as a means of designing instructions in Nigerian junior secondary schools.

- $\quad$ The Learning Activity Package should be particularly introduced into system approach to instruction in basic science and technology at all levels of teacher education.

- Teachers in secondary schools should be encouraged by education authorities in Nigeria to use LAP in teaching.

- Teachers should be encouraged and motivated to attend conferences, seminars, workshops so as to be abreast of the innovations in teaching.

\section{References}

Abonyi, O.S \& Ibe, E. (2014). Effects of Exposure to Constructivist Instruction on Interest of Male and Female Science Students. International Journal of Scientific and Engineering Research 5 (2), 1558-1561.

Abu, A.O. (1998). The Effectiveness of Individualized and Lecture Instructional Methods of Teaching Biology at the Senior Secondary Level of Education. Unpublished M. Ed Thesis. Ahmadu Bellow University Zaria. 
Abu. A. O. (2001) Resource utilization in classroom: The effect of learning activity package to teach biology at the senior secondary level of education. JSTAN 40 (2) $103-106$.

Adedapo, Y.A. (2013). Impart of Three Microteaching Modes on Trainee-Teachers' Learning Outcomes in Selected Teaching Skills. Unpublished PhD thesis. Ago Iwoye, Ogun State, Nigeria: Olabisi Onabanjo University.

Bennett, J., (2013). Teaching and Learning Science. London: Continuum.

Berube, C.T. (2008). The Unfinished Quest; the Plight of Progressive Science. Education in the Age of Standards. Charlotte, NC: linformation Age.

Betiku, O.F. (2001). Differential performance of newly introduced topics in senior secondary school mathematics for teacher education. A Journal of the Association of Teacher Educators in Nigeria, 2 (2), 117-112.

Bilesanmi-Awoderu, J.B, Afuwape, M.O \& Jolaosho, F.A (2017). Boosting achievement using individualised and demonstration strategies in biology: How do male and female students behave in Nigeria? British Journal of Education, 5, (3) 51-59.

Burnside, P. (1991). Computers as a Writing Tool - Learning Package for Eight Grade Students. Master's Thesis. New York. Institute of Technology. U.S.A.

Cardarelli, S. (1972).The LAP: A Feasible Vehicle of Individualization. Journal of Education Technology.12 (3) 23-29.

Nigeria Educational Research and Development Council (2007). 9-Year basic Education Curriculum; Basic science and Technology for middle Basic Education, Primaries 4-6. P55 - 67

Njoku, C.O. \& Akamobi, I. (n.d). Effect of learning activity package (lap) on students' academic achievement in agricultural science. $\begin{array}{llll}\text { Retrieved October } & \text { 1, } & \text { from }\end{array}$ http://www.globalacademicgroup.com/journals/pristine/EFFECT\%200F\%20LEARNING\%20ACTIVITY\%20PACKAGE\%20_LAP _\%200N\%20STUDENTS\%20ACADEMIC\%20ACHIEVEMENT\%20IN\%20AGRICULTURAL\%20SCIENCE\%20CHIGOZIE\%200.\%20NJOKU\%20AND\%20DR.\%20I.\%20AKAMOBI.pdf

Clark, D.R. (2011). Visual, Auditory and Kinesthetic Learning Style (VAK). Retrieved on 8 January, 2019 from http/www.nwlink.com/donlark/hrd/styles/vakt.html

Ekon, E.E. (2013). Effect of Five-Step Conceptual Change Instructional Model on Students' Perception of Their Psychosocial Learning Environment. (Unpublished doctoral dissertation). Nsukka: University of Nigeria.

Ezema, H.C.U. (2004). Effective Science and Computer Education. Abuja: Farray Digital Prints.

Federal Ministry of Education, (2008). The Development of Education, National Report of Nigeria Abuja. http://www.emeraldinsight.com/10.1108/00242539410134589

Ferdinand, J.B. (2007). Teachers' Effectiveness and Internal Efficiency in Primary Education. Retreived September 5, 2019 from http://www.edu/edupolicies/schls/such/op/employa.

Graf, S., Kinshuk, R. \& Liu, T.C. (2009). Supporting teachers in identifying students' learning styles in learning Management System. An Automobile Student Modelling Approach. Educational Technology \& Society, 12(4), 3 - 14. 
Hattie, K.A. (2011). Effect of Dick \& Carey instructional strategy on their students' cognitive achievement in physics concepts among higher basic stage students. Journal for Research-Science. 26(9),2041-2064.

Keefe, J.W. (1979). Learning style: An overview. In NASSP's /Student Learning Styles: Diagnosing and Proscribing Program, 4-17. Reston, VA: National Associations of Secondary School Principals.

Mandor, A.K. (2002). Effect of constructivist based instructional model on acquisition of science process skill among junior secondary students. Unpublished med project. Nsukka: University of Nigeria.

Neboh, O. (2009). Effect of Learning Activity Package (LAP) on Students' Achievement and Retention in Senior Secondary School Biology. Thesis. Nsukka: University of Nigeria.

NERDC. (2007). 9- Year basic Education Curriculum; Basic science and Technology for middle Basic Education, Primaries 4-6. P55 67

O'Bannon, B. (2002). Planning for instruction (instructional method). Retrieved October 30, 2019 from http://www.feutked/rbonannon/in/strategies/htm

Ogonnaya, U.P., Okafor, G., Abonyi, O.S., \& Ugama, J.O. (2016). Effects of concept mapping instruction approach on students' achievement in basic science. Journal of Education and Practice, 7(8), 79-84.

Ogundokun, M.O. (2011). Learning Style, School Environment and Test Anxiety as correlates of Learning Outcomes among Secondary School Students. LIfe Psychology Journal, 2(2), 247 - 260.

Ogunkola, A.S. (2008). Education: An Unprofitable Industry in Nigeria. A Postgraduate School. Interdisciplinary Research Discourse. Ibadan: Ibadan University Press.

Ogunnika, O. A (2018). Adequacy and Usage of Eko Project Instructional Materials as perceived by Junior Secondary School Biology Teachers in Lagos State of Nigeria. Unpublished dissertation, Ago Iwoye, Ogun State of Nigeria: Olabisi Onabanjo University.

Olurinola, O.D. (2015). Effects of Power Point and Multiple Mouse Presentation Media on Junior Secondary School Students Learning Outcomes in Cultural and Creative Art. Unpublished Ph.D Thesis., Ago Iwoye: Olabisi Onabanjo University.

Omole, A.E. (2003).Task on Government Technology. Retrieved September 5, 2019 from wwwvanguardngr.com/

Osuolale, O.J. (2014). Problem of teaching and learning science in junior secondary schools in Nasarawa State. Nigeria Journal of Education and Practice, 5 (3). 109-118.

Oyedeji (2010).Effective teaching of mathematics and science in junior secondary school in Bayelsa state. A workshop organized by U.I consultancy services in collaboration with Bayelsa state Universal Basic Education Board.

Sadeghi, N., Kasim, Z.M., Tan, B.H. \& Abdullah, F.S. (2012). Learning styles, personality types and reading comprehension performance. English Language Teaching, 5(4):116-123.

Sander, W. (2001).Chicago Public Schools and Student Achievement. Urban Education, 36 (1), 27-38. 